\title{
AUDIT
}

\section{Variable use of endoscopic haemostasis in the management of bleeding peptic ulcers}

\author{
S Mahadeva, M Linch, M Hull
}

Postgrad Med J 2002;78:347-351

See end of article for authors' affiliations

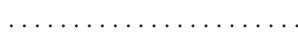

Correspondence to: Dr M Hull, Academic Unit of Medicine, St James's University Hospital, Leeds LS9 7TF, UK;

M.A.Hull@leeds.ac.uk

Submitted

30 October 2001

Accepted

20 February 2002

\begin{abstract}
Background: Randomised controlled trials (RCTs) have shown that endoscopic haemostasis is beneficial for patients with a bleeding peptic ulcer. The relevance of such data to management outside of RCTs is unclear. Therefore we examined management of patients with a bleeding peptic ulcer in a UK teaching hospital.

Methods: All patients who underwent upper gastrointestinal (UGI) endoscopy for bleeding peptic ulcer between 1997 and 1999 were identified from an endoscopy database and the clinical records reviewed retrospectively.

Results: A total of 872 patients underwent UGI endoscopy for presumed acute UGI haemorrhage; 179 $(21 \%)$ had an endoscopic diagnosis of bleeding peptic ulcer. Seventy nine patients had a peptic ulcer with stigmata of recent haemorrhage (SRH) but only $61(77 \%)$ of these patients received endoscopic haemostasis $(77 \%$ adrenaline, $23 \%$ combination therapy). Re-bleeding occurred in 24 patients with $\mathrm{SRH}$ in whom transfusion requirement was the sole predictor of re-bleeding. The re-bleeding rate among patients who received adrenaline was $25 \%(n=12)$, compared with $57 \%(n=8)$ in the combination group and $31 \%(n=4)$ in those who did not receive endoscopic haemostasis. Patients who received combination endoscopic haemostasis had an increased incidence of active bleeding $(p=0.007)$ and an increased transfusion requirement $(p=0.002)$. Eleven of 20 patients who re-bled had repeat endoscopic haemostasis, with $45 \%$ eventually requiring surgery.

Conclusions: Results of endoscopic management of bleeding peptic ulcers in the unit studied differ markedly from those published by specialised centres. The data reported here suggest that increased standardisation of endoscopic haemostasis is required, especially in units with provision for emergency "out-of-hours" endoscopy, performed by several individuals of different grades.
\end{abstract}

$\mathrm{P}$ eptic ulceration remains the commonest cause of acute upper gastrointestinal (UGI) bleeding, accounting for $30 \%-50 \%$ of cases. ${ }^{1-3}$ In the United Kingdom, bleeding peptic ulcer accounts for approximately 15000 hospital admissions per year, ${ }^{2}$ with a district general hospital admitting one to two patients with a bleeding peptic ulcer per week. Although bleeding ceases spontaneously in at least $80 \%$ of cases, a subgroup of patients either continue to bleed or re-bleed at a later time, ${ }^{45}$ and this is associated with an increased mortality. Upper gastrointestinal endoscopy has not only been useful in stratifying this "high risk" group of patients, but has evolved over the last two decades into the initial therapeutic intervention of choice. ${ }^{67}$

Since the landmark study by Chung et al, ${ }^{8}$ in which adrenaline injection of bleeding ulcers was shown to be significantly better than no treatment, multiple single centre randomised controlled trials (RCTs) have confirmed the efficacy of endoscopic haemostasis. ${ }^{9-20}$ Endoscopic haemostasis modalities that have been proved to be beneficial include either single agents (adrenaline or a sclerosant ${ }^{81012}$ ) or combination therapy (usually adrenaline/sclerosant plus a thermal modality such as heater probe application ${ }^{11}{ }^{13-15}$ ). As recurrent bleeding after initial haemostasis is the single most important prognostic factor contributing to mortality, ${ }^{5}$ the re-bleeding rate has been a useful reference endpoint to compare various trial results. Peptic ulcers which have an actively bleeding/ spurting vessel, non-bleeding visible vessel, or adherent clot seen at initial endoscopy are known to have re-bleeding rates of $70 \%-95 \%, 50 \%-70 \%$, and $30 \%-45 \%$ respectively. ${ }^{6}$ Although trials of endoscopic haemostasis have clearly demonstrated reduced re-bleeding overall, the results have been very variable. While some units have reported re-bleeding rates between $5 \%-10 \%$ using either single or combination therapy, ${ }^{9-14}$ others have reported re-bleeding rates as high as $40 \%{ }^{18-20}$ The different endoscopic modalities used may be an explanation for variable re-bleeding rates, although other factors such as endoscopist experience and patient co-morbidity are also likely to have contributed to variability in published outcome data.

A possible role for therapeutic endoscopy in peptic ulcer re-bleeding after initial endoscopic haemostasis has been addressed recently. ${ }^{21}$ Traditionally, patients who have re-bled after initial endoscopic haemostasis have been referred for immediate surgery. However Lau and colleagues recently demonstrated that $73 \%$ of patients who had repeat endoscopic haemostasis for re-bleeding after initial endoscopic haemostasis achieved long term control of bleeding and thus avoided emergency surgery. ${ }^{21}$ This approach was associated with fewer complications and shorter duration of hospital stay than immediate surgery after re-bleeding but there was no significant difference in mortality between the two groups. ${ }^{21}$

The relevance of outcome data for endoscopic haemostasis from specialised units (in the setting of a RCT) to everyday practice remains uncertain. To examine this further, we analysed endoscopic management of bleeding peptic ulcers in our institution, a large teaching hospital (1115 beds) which has operated a 24 hour emergency UGI endoscopy service for the last six years. All patients referred with acute UGI bleeding have been endoscoped either within 24 hours on the next available routine list, or immediately if the patient was

Abbreviations: RCTs, randomised controlled trials; $\mathrm{SRH}$, stigmata of recent haemorrhage; UGI, upper gastrointestinal 


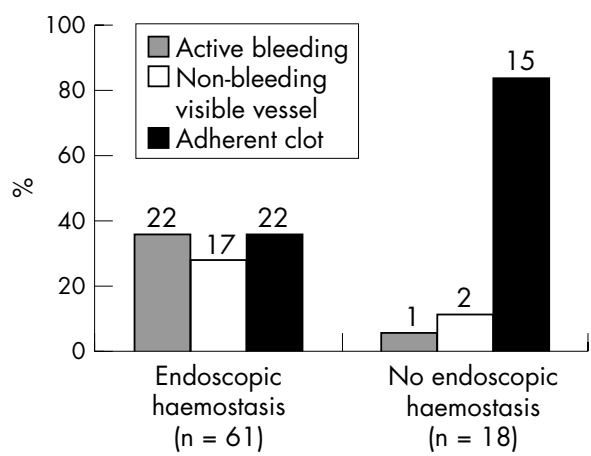

Figure 1 SRH characteristics of peptic ulcers in patients who did or did not receive endoscopic haemostasis. The number above each column denotes the number of patients with a particular SRH type.

haemodynamically unstable. Each UGI endoscopy was performed by one of several consultant gastroenterologists or specialist registrars with assistance from two nurses.

\section{METHODS}

\section{Data retrieval}

A retrospective review of all UGI endoscopy reports on an Endoscribe Database (Astra) between 1 January 1997 and 31 December 1999 with the indications of "haematemesis" and/or "melaena" was undertaken. Patients with peptic ulcer disease as the sole cause of UGI bleeding were identified. Patients with concurrent gastro-oesophageal varices were excluded. The following information was obtained from the database: endoscopist grade-that is, registrar (1-2 years endoscopy experience), senior registrar (3-5 years endoscopy experience), or consultant ( $>5$ years endoscopy experience), location of ulcer, presence and type of stigmata of recent haemorrhage ( $\mathrm{SRH}$; active bleeding, non-bleeding visible vessel, or adherent clot), type of endoscopic haemostasis (nil, adrenaline, combination therapy) performed and if primary haemostasis was achieved at the end of the procedure. Patients with peptic ulceration that did not have SRH had either a clean ulcer base or a flat pigmented spot. Difficult ulcer location, which has been associated with suboptimal endoscopic haemostasis outcome, was defined as either high lesser curve gastric ulcer or posterior wall duodenal ulcer. ${ }^{22}$ The time that acute UGI endoscopy was performed; "out-ofhours" (between $6 \mathrm{pm}$ and 8 am the next day), at the weekend or on a routine list, was also noted.

The clinical records of patients with bleeding peptic ulcers were also reviewed. We collated information on demographic data (age and sex); evidence of re-bleeding after initial endoscopy (defined as a further episode of haematemesis and/or fresh melaena associated with hypotension-that is, systolic blood pressure $<100 \mathrm{~mm} \mathrm{Hg}$ ); subsequent management of re-bleeding (repeat endoscopic haemostasis and/or surgery); length of stay in hospital, and eventual outcome (that is, discharge from hospital or death). Mortality was subdivided into early ( $<30$ days) and late ( $>30$ days). As co-morbid disease has been shown to be associated with a worse outcome after endoscopic haemostasis, this was also examined. Our classification of co-morbidity (defined as cardiovascular: known ischaemic heart disease, valvular heart disease, or congestive cardiac failure; respiratory: known chronic obstructive airways disease, pneumonia, or pulmonary embolism; renal failurethat is, on regular dialysis; cerebrovascular disease-residual deficit or recurrent transient ischaemic attacks; cancer and other) was based on a similar method used by Khuroo et al, ${ }^{23}$ which only included the first three disease systems. Blood transfusion requirement within 24 hours of the initial bleed was obtained from Blood Transfusion Service records.

\section{Statistical analysis}

Differences between patients receiving different endoscopic management were compared using either one way analysis of variance or the Kruskal-Wallis test. Variables which were demonstrated to be significantly different by univariate analysis were entered into a multivariate logistic regression model in order to determine independent predictors of re-bleeding. Statistical significance was assumed at a p value of 0.05 .

\section{RESULTS \\ Acute UGI bleeding caused by peptic ulceration}

A total of 872 patients underwent UGI endoscopy for presumed acute UGI bleeding during the three year review period. Of these, $179(21 \%)$ patients had an endoscopic diagnosis of peptic ulceration as the sole cause of an acute UGI bleed. Clinical notes were available for review in 163 (91\%) cases. Seventy nine UGI endoscopies (44\%) were performed "out-of-hours" or at weekends. The mean (SEM) age of the patients was 65 (1) years (range 26-96) and the male:female ratio was 2.6:1. Overall, $46 \%$ of patients fulfilled one or more co-morbid disease categories.

\section{Endoscopic management of bleeding peptic ulcer with SRH}

Of the 163 patients with a bleeding peptic ulcer who had clinical records available for review, $79(48 \%)$ had SRH visible at initial endoscopy. Sixty one of 79 (77\%) patients with SRH received endoscopic haemostasis at initial endoscopy while 18 (23\%) patients did not (fig 1). Among the patients who

Table 1 Patient characteristics, transfusion requirement, and outcome of patients who had SRH visible at initial endoscopy

\begin{tabular}{|c|c|c|c|c|}
\hline & \multicolumn{3}{|c|}{ Endoscopic haemostasis types } & \multirow[b]{2}{*}{$\mathrm{p}$ Value } \\
\hline & $\begin{array}{l}\text { No endoscopic } \\
\text { haemostasis } \\
(n=18)\end{array}$ & $\begin{array}{l}\text { Adrenaline } \\
(n=47)\end{array}$ & $\begin{array}{l}\text { Combination } \\
(n=14)\end{array}$ & \\
\hline Mean age (range) & $67(33-93)$ & $66(34-93)$ & $64(34-91)$ & $0.8^{*}$ \\
\hline Co-morbidity $(\%)$ & 56 & 45 & 71 & $0.2 \dagger$ \\
\hline Active bleeding (\%) & 6 & 34 & 57 & $0.007 \dagger$ \\
\hline \multicolumn{5}{|l|}{ Endoscopist grade $(\%)$} \\
\hline Registrar & 44 & 42 & 36 & \\
\hline Senior registrar & 28 & 38 & 50 & $0.97 \dagger$ \\
\hline Consultant & 28 & 20 & 14 & \\
\hline Difficult ulcer location (\%) & 28 & 32 & 29 & $0.9 \dagger$ \\
\hline Mean (SEM) transfusion requirement (units) & $2.7(0.6)$ & $4.0(0.5)$ & $6.9(0.8)$ & $0.002 *$ \\
\hline Re-bleeding rate $(\%)$ & 31 & 25 & 57 & $0.05 \dagger$ \\
\hline
\end{tabular}


Table 2 Co-morbidity of patients with SRH visible at initial endoscopy; values are number (\%)

\begin{tabular}{llll}
\hline & \multicolumn{2}{l}{ Endoscopic haemostasis types } \\
\cline { 2 - 4 } Co-morbidity & $\begin{array}{l}\text { No endoscopic } \\
\text { haemostasis }\end{array}$ & Adrenaline & Combination \\
\hline Absent & $8(44)$ & $26(55)$ & $4(29)$ \\
Present & $10(56)$ & $21(45)$ & $10(71)$ \\
Cardiovascular & $3(17)$ & $9(19)$ & $4(29)$ \\
Respiratory & $1(6)$ & $1(2)$ & $2(14)$ \\
Cerebrovascular disease & $3(16)$ & $6(13)$ & 0 \\
Cancer & $2(11)$ & $3(6)$ & $2(14)$ \\
Renal failure & $1(6)$ & 0 & $2(14)$ \\
Other & 0 & $2(5)$ & 0 \\
\hline
\end{tabular}

received initial endoscopic haemostasis, 39 (64\%) cases had active bleeding or a non-bleeding visible vessel at the time of endoscopy, compared with three (17\%) in the group that did not receive any initial endoscopic haemostasis (fig l). In contrast, $15(83 \%)$ of the patients who did not receive initial endoscopic haemostasis had adherent clot compared with 22 (36\%) patients who did receive initial endoscopic haemostasis (fig 1).

\section{Outcome of patients receiving different endoscopic haemostasis techniques}

Of the patients who received endoscopic haemostasis, 47 (77\%) had adrenaline ( $1: 10000$ dilution) injection only while 14 had combination endoscopic haemostasis (adrenaline plus heater probe, $\mathrm{n}=12$; adrenaline plus thrombin injection, $\mathrm{n}=2$ ) (fig 2). Patient characteristics, endoscopic findings, and blood transfusion requirements are documented in table 1. Complete haemostasis was achieved at the end of the endoscopic procedure in all but two patients (96\%). Twelve of 47 patients (25\%) re-bled after adrenaline endoscopic haemostasis ( fig 2 ). In the combination endoscopic haemostasis group, 8/14 patients $(57 \%)$ re-bled after initial endoscopic haemostasis (fig 2). Univariate analysis showed that the transfusion requirement $(p=0.002)$ and the presence of active bleeding at initial endoscopy $(p=0.007)$ were significantly higher in the group of patients who received combination endoscopic haemostasis. A higher proportion of patients receiving combination endoscopic haemostasis had co-morbidity than the other two groups (table 2) but this did not reach statistical significance. Although differences in the grade of endoscopist between the three groups of patients with SRH were not statistically significant, combination endoscopic haemostasis was used more by senior registrars compared with other grades (table 1). Logistic regression analysis revealed that transfusion requirement was the only independent predictor of rebleeding $(p=0.002)$. In the group of patients with SRH who did not receive initial endoscopic haemostasis, 4/18 (31\%) had re-bleeding after initial diagnostic endoscopy. Only 2/84 patients who were reported to have no SRH re-bled (which was managed surgically with one mortality).

\section{Management of re-bleeding after initial endoscopy}

Among the patients who re-bled after receiving adrenaline endoscopic haemostasis, four patients had repeat endoscopic haemostasis (all combination), two died (one immediate death and the other did not have further intervention due to severe cerebrovascular disease), and six underwent surgery immediately (fig 2). Of those that re-bled after combination endoscopic haemostasis, seven had repeat endoscopic haemostasis (all combination) and one patient had surgery immediately. Five of 11 (45\%) patients who had repeat endoscopic haemostasis required salvage surgery for continued bleeding (fig 2). Nine of 11 (81\%) patients who received repeat endoscopic haemostasis had co-morbidity compared with 3/7 (43\%) who underwent surgery immediately for re-bleeding. The group of patients in whom repeat endoscopic haemostasis failed had $100 \%$ co-morbidity and a significantly higher mean transfusion requirement compared with those who had successful repeat endoscopic haemostasis for re-bleeding or immediate surgery (table 3$)$. Two of 11 (18\%) patients who had repeat endoscopic haemostasis suffered early mortality compared with $1 / 7$ (14\%) patients who had immediate surgery. Surgery for re-bleeding or secondary bleeding after failed endoscopic haemostasis consisted of under-running of the ulcer $(n=6)$, under-running of the ulcer with pyloroplasty and vagotomy $(n=3)$, excision of ulcer and vessel underrunning $(n=1)$, gastroenterostomy $(n=1)$, and partial gastrectomy $(n=1)$. Patients who had re-bleeding from an ulcer in a "difficult" location were more likely to be referred for immediate surgery $(57 \%)$ than those whose ulcer was elsewhere $(20 \%)$. The length of hospital stay after acute UGI bleeding was significantly longer in those patients who had repeat endoscopic haemostasis but eventually required surgery (table 3). However a similar duration of hospital stay was noted in those who underwent surgery or successful repeat endoscopic haemostasis for re-bleeding (table 3).

\section{Outcome of patients who did not receive endoscopic haemostasis}

In the group of patients with SRH who did not receive initial endoscopic haemostasis the outcome of the four patients that re-bled were as follows: one suffered early mortality, two received endoscopic haemostasis (one of which required salvage surgery for continued bleeding but did not survive), and a further patient had surgery immediately.

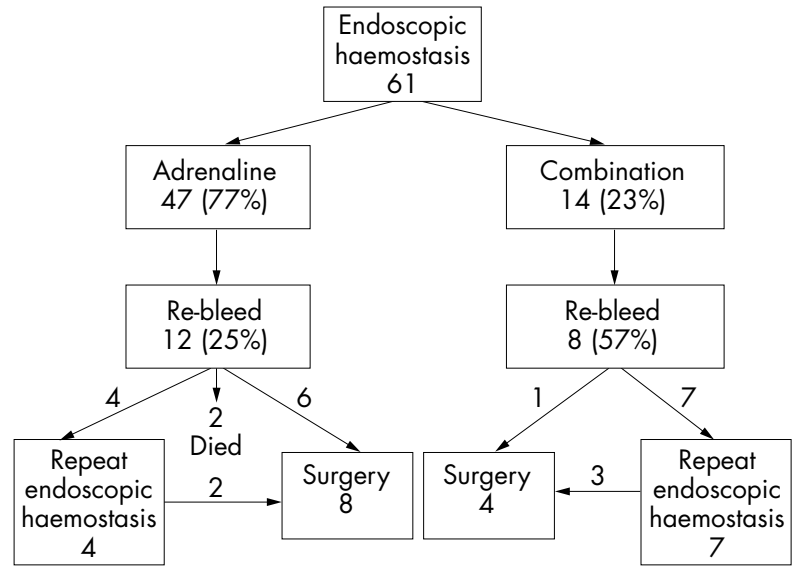

Figure 2 Outcome of patients who received endoscopic haemostasis. 
Table 3 Patient characteristics, transfusion requirement, and outcome of patients who underwent surgery or repeat endoscopic haemostasis after re-bleeding

\begin{tabular}{|c|c|c|c|}
\hline & \multicolumn{3}{|l|}{ Treatment modalities } \\
\hline & \multirow{2}{*}{$\begin{array}{l}\text { Immediate surgery } \\
(n=7)\end{array}$} & \multicolumn{2}{|c|}{ Repeat endoscopic haemostasis } \\
\hline & & Failed $(n=5)$ & Successful $(n=6)$ \\
\hline Mean age (range) & $69(47-89)$ & $72(58-81)$ & $58(33-87)$ \\
\hline Co-morbidity (\%) & 43 & 100 & 67 \\
\hline Active bleeding (\%) & 57 & 60 & 50 \\
\hline \multicolumn{4}{|l|}{ Endoscopist grade $(\mathrm{n})$} \\
\hline Registrar & 4 & 2 & 2 \\
\hline Senior registrar & 3 & 2 & 3 \\
\hline Consultant & 0 & 1 & 1 \\
\hline \multicolumn{4}{|l|}{ Initial endoscopic haemostasis type (\%) } \\
\hline Adrenaline & 86 & 40 & 33 \\
\hline Combination & 14 & 60 & 67 \\
\hline No (\%) with difficult ulcer location & $3(57)$ & $1(20)$ & 0 \\
\hline Mean (SEM) total transfusion (units) & $11.5(1.54)$ & $15.8(2.71)$ & $9.5(2.24)$ \\
\hline Mean (SD) length of inpatient stay (days) & $16(3)$ & $41(21)$ & $17(4)$ \\
\hline Mortality (n) & 1 & 1 & 1 \\
\hline
\end{tabular}

\section{Mortality of patients with bleeding peptic ulcer}

The 30 day mortality rate for all patients with bleeding peptic ulcers was $11.6 \%$. Subgroup analysis revealed 30 day mortality rates of $6 \%$ in the group of patients who received no SRH, $16.4 \%$ in the SRH group that received initial endoscopic haemostasis, and $22.2 \%$ in the SRH group who did not receive initial endoscopic haemostasis.

\section{DISCUSSION \\ Use of endoscopic haemostasis for peptic ulcers with SRH}

This retrospective study of the endoscopic management of bleeding peptic ulcers in a large teaching hospital has raised several important issues. Firstly, only $77 \%$ of patients with $\mathrm{SRH}$ at the ulcer base received endoscopic haemostasis at initial endoscopy. This was explained largely by reduced use of endoscopic haemostasis in cases with adherent clot at the ulcer base. Although endoscopic haemostasis has previously not been advocated for peptic ulcers with adherent clot alone at the base and many endoscopists are hesitant to disturb adherent clot when there is no active bleeding, recent evidence suggests otherwise. ${ }^{24-26}$ Laine et al have shown that aggressive irrigation of adherent clots can reveal "higher risk" lesions in up to $28 \%$ of cases. ${ }^{24}$ The final analysis from a recent multicentre study has also shown that the re-bleeding rate of patients with adherent clot at the ulcer base was significantly better after endoscopic haemostasis compared with medical treatment only $(5 \% v 34 \%) .{ }^{26}$ High interobserver variability in differentiation between a non-bleeding visible vessel and adherent clots is another reason for treating the latter endoscopically. ${ }^{27-29}$

\section{Variability of endoscopic haemostasis techniques}

In cases where endoscopic haemostasis was applied, the type which was used was variable. The large number $(n=19)$ and variable experience of endoscopists and the introduction of novel modalities, such as thrombin, during the review period is likely to have contributed to this lack of uniformity of endoscopic haemostasis.

\section{Re-bleeding rates after endoscopic haemostasis}

Another important point relates to the re-bleeding rate in patients who received endoscopic haemostasis. Although the re-bleeding rate after adrenaline endoscopic haemostasis (25\%) was comparable to published RCT data, ${ }^{15-19}$ the re-bleeding rate in patients who received combination endoscopic haemostasis was particularly high (57\%) in comparison with data from RCTs that have randomised only patients with actively bleeding ulcers. ${ }^{10} 12151921$ However, the size of the acute UGI bleed (measured by size of blood transfusion) in the unselected group of patients who received combination endoscopic haemostasis during our review period was higher than in published RCTs (reported between 3-5 units). ${ }^{8}{ }^{12}{ }^{15-17}$ This may explain the high re-bleeding rate in this group of patients as size of the acute bleed (measured by presence of shock, haemodynamic instability, and transfusion requirement) has been demonstrated to be an important predictor of re-bleeding. ${ }^{67}$ Another possible explanation which deserves further (prospective) study is that, outside of RCTs, combination endoscopic haemostasis may be less efficacious than adrenaline injection alone.

\section{Management of patients with re-bleeding after initial endoscopy}

Eleven of 20 patients who re-bled had repeat endoscopic haemostasis. Patients who received repeat endoscopic haemostasis had a higher prevalence of co-morbidity than those who underwent emergency surgery immediately. The position of the ulcer and "ease" of endoscopic haemostasis at initial endoscopy also appears to have been a factor in the decision whether to refer a patient for immediate surgery or repeat endoscopy as those cases with a difficult ulcer location are over-represented in the group who received immediate surgery. Forty five per cent of the patients who had repeat endoscopic haemostasis eventually required salvage surgery compared with $27 \%$ of patients who had repeat endoscopic haemostasis for re-bleeding in the RCT performed by Lau et al. ${ }^{21}$ Furthermore, the failed repeat endoscopic haemostasis group had a significantly higher transfusion rate and longer inpatient stay compared with those who had immediate surgery (table 3 ). Although mortality rates in the immediate surgery and repeat endoscopic haemostasis groups were similar, the duration of hospital stay was longer for those patients who received repeat endoscopic haemostasis (especially if that modality failed with subsequent surgery). However, the small number of patients does not allow a definitive conclusion to be drawn. Despite reviewing endoscopic data in a large unit over a three year period, we were still not able to analyse a sufficient number of cases of re-bleeding after endoscopic haemostasis. Future analyses of patient management after initial endoscopic haemostasis are likely to require regional audit in order to generate sufficient power. Recently, it has been demonstrated that high dose intravenous acid suppression therapy reduces re-bleeding after endoscopic haemostasis of peptic 
ulcers with SRH. ${ }^{30}$ However, during our review period (199799), intensive acid suppression was not used after endoscopic haemostasis for bleeding peptic ulcer at St James's University Hospital.

Our data have revealed a lower proportion of patients with a diagnosis of bleeding peptic ulcer than previous published reports of audits of acute UGI bleeding. ${ }^{23}$ One reason for this may have been bias due to the retrospective nature of the study. A more likely explanation is the less stringent criteria for evidence of gastrointestinal bleeding that was applied in this study when compared with the published literature. ${ }^{2}$ Only cases of witnessed haematemesis or melaena, by medical or nursing staff, were analysed in previous studies. Our study included all cases of haematemesis and/or melaena, both witnessed and self reported, for which the attending medical team had requested UGI endoscopy. Therefore, our series is likely to have included a number of cases with less or no pathology and lowered the proportion of peptic ulcers presenting as an acute UGI bleed.

The results presented here have implications for the British Society of Gastroenterology working party report on provision of endoscopy related services which has recently been published. ${ }^{31}$ Our study suggests that specific guidelines for emergency endoscopic management should be incorporated in order to minimise variability of practice, especially for units where provision of emergency UGI endoscopy is dependent on multiple endoscopists. Our unit now uses a specific protocol for management of patients with a bleeding ulcer which incorporates specific guidelines on endoscopic haemostasis technique. However, the need for surgery or repeat endoscopic haemostasis is still left to individual gastroenterologists and surgeons in collaboration.

In conclusion, this study has demonstrated variability of endoscopic management of patients with bleeding peptic ulcer and higher re-bleeding rates after endoscopic haemostasis compared with those reported in RCTs. Although an increase in bleed severity and co-morbidity may account for higher re-bleeding rates, variability in operator experience and haemostatic techniques are also likely to be contributory.

\section{ACKNOWLEDGEMENTS}

The authors wish to thank the staff of the Endoscopy Unit at St James's University Hospital for their help during the study.

MAH is funded by the MRC (UK).

\section{Authors' affiliations}

S Mahadeva, M Linch, M Hull, Academic Unit of Medicine, St James's University Hospital, Leeds, UK

\section{REFERENCES}

1 Laine L, Peterson WL. Bleeding peptic ulcer. N Engl J Med 1994;331:717-26.

2 Rockall TA, Logan RFA, Devlin HB, et al. Incidence of and mortality from acute upper gastrointestinal haemorrhage in the United Kingdom. BM 1995:311:222-6.

3 Kurata JH, Corboy ED. Current peptic ulcer time trends: an epidemiological profile. J Clin Gastroenterol 1988;10:259-68.

4 Allan R, Dykes P. A study of the factors influencing mortality rates from gastrointestinal haemorrhage. Q J Med 1976;45:533-50.

5 Rockall TA, Logan RFA, Devlin HB, et al. Risk assessment after acute upper gastrointestinal haemorrhage. Gut 1996;38:316-21.
6 Rollhauser C, Fleischer DE. Current status of endoscopic therapy for ulcer bleeding. Ballieres Clin Gastroenterol 2000;14:391-410.

7 Savides TJ, Jensen DM. Therapeutic endoscopy for nonvariceal gastrointestinal bleed. Gastroenterol Clin North Am 2000;29:465-87.

8 Chung SC, Leung JW, Steele RJ, et al. Endoscopic injection of adrenaline for actively bleeding ulcers: a randomised trial. $B M$ 1988;296:1631-3

9 Villanueva C, Balanzo J, Espinos JC, et al. Endoscopic injection therapy of bleeding ulcer: a prospective and randomised comparison of adrenaline alone or with polidocanol. J Clin Gastroenterol 1993; 17:195-200.

10 Chung SC, Leong HT, Chan AC, et al. Epinephrine or epinephrine plus alcohol for injection of bleeding ulcers: a prospective randomised trial. Gastrointest Endosc 1996:43:591-5.

11 Kubba AK, Murphy W, Palmer KR. Endoscopic injection for bleeding peptic ulcer: a comparison of adrenaline alone with adrenaline plus human thrombin. Gastroenterology 1996;111:623-8.

12 Lin HJ, Tsai YT, Lee SD, et al. A prospectively randomised trial of heat probe thermocoagulation versus pure alcohol injection in nonvariceal peptic ulcer haemorrhage. Am J Gastroenterol 1988;83:283-6.

13 Laine L. Multipolar electrocoagulation versus injection therapy in the treatment of bleeding peptic ulcers. A prospective randomised trial. Gastroenterology 1990;99:1303-6.

14 Carter R, Anderson JR. Randomised trial of adrenaline injection and laser photocoagulation in the control of haemorrhage from peptic ulcer. Br J Surg 1994;81:869-71.

15 Chung SC, Lau JY, Sung JJ, et al. Randomised comparison between adrenaline injection alone and adrenaline injection plus heater probe treatment for actively bleeding ulcers. BM 1997:314:1307-1 1.

16 Choudari CP, Rajgopal C, Palmer KR. Comparison of endoscopic injection therapy versus the heater probe in major peptic ulce haemorrhage. Gut 1992;33:1159-61.

17 Chung SC, Leung J, Sumg J, et al. Injection or heat probe for bleeding ulcer. Gastroenterology 1991;100:33-7.

18 Rutgeerts P, Vantrappen G, Broeckaert L, et al. Comparison of endoscopic polidoconal injection and YAG laser therapy for bleeding peptic ulcers. Lancet 1989;27:1 164-7.

19 Lin HJ, Perng CL, Lee SD. Is sclerosant injection mandatory after an epinephrine injection for arrest of peptic ulcer haemorrhage? A prospective, randomised, comparative study. Gut 1993;34:1182-5.

20 Lin HJ, Tseng GY, Perng CL, et al. Comparison of adrenaline injection and bipolar electrocoagulation for the arrest of peptic ulcer bleeding. Gut 1999:44:715-19.

21 Lau JYW, Sung JY, Lam Y, et al. Endoscopic retreatment compared with surgery in patients with recurrent bleeding after initial endoscopic control of bleeding ulcers. N Engl J Med 1999;340:751-6.

22 Brullet E, Campo R, Bedos G, et al. Site and size of bleeding peptic ulcer: is there any relation to the efficacy of hemostatic sclerotherapy? Endoscopy 1991:23:73-5.

23 Khuroo MS, Yattoo GN, Javid G, et al. A comparison of omeprazole and placebo for bleeding peptic ulcers. N Engl J Med 1997;336:1054-8

24 Laine L, Stein C, Sharma V. A prospective outcome study of patients with clot in an ulcer and the effect of irrigation. Gastrointest Endosc 1996:43:107-10.

25 Jensen DM, Kovacs TOG, Jutabha R, et al. Initial results of a multicenter randomised controlled trial of medical vs combination endoscopic therapy for prevention of recurrent severe ulcer haemorrhage from non-bleeding adherent clots. Gastrointest Endosc 1996;43:352-5.

26 Bleau BL, Gostout CJ, Shaw M, et al and the group at ACS. Final results: rebleeding from peptic ulcers associated with adherent clots: a randomised controlled study comparing endoscopic therapy with medical therapy. Gastrointest Endosc 1997:41:A251.

27 Lau JYW, Sung JJY, Chun ACW, et al. Stigmata of haemorrhage in bleeding peptic ulcers: an inter-observer agreement study among international experts. Gastrointest Endosc 1997;46:33-6.

28 Laine L, Freeman ML, Cohen $\mathrm{H}$. Lack of uniformity in evaluation of endoscopic prognostic features of bleeding ulcers. Gastrointest Endosc 1994:40:411-17.

29 Bour B, Person B, Cales P, et al. Interobserver agreement on endoscopic diagnosis of bleeding peptic ulcers. Gastrointest Endosc 1997:46:27-32.

30 Lau JYW, Sung JJY, Lee KKC, et al. Effect of intravenous omeprazole on recurrent bleeding after endoscopic treatment of bleeding peptic ulcers. N Engl J Med 2000;343:310-16.

31 Working Party of the British Society of Gastroenterology. Provision of endoscopy related services in district general hospitals. London: British Society of Gastroenterology, 2001. 